\title{
PERBANDINGAN PRONOMINA PERSONA BAHASA INDONESIA DENGAN BAHASA MALAYSIA: TINJAUAN SEMANTIS
}

\author{
Aswan, Nuny Sulistiany Idris, dan Ida Widia \\ Universitas Pendidikan Indonesia \\ email: hikayatashwansha@upi.edu
}

\begin{abstract}
(Title: Comparison of Personal Pronomins Indonesian Language With Malaysia: Semantic Review). Indonesian and Malaysian are languages that are often debated because they have similarities and similarities. This happens because Indonesian and Malaysian are rooted in Malay. Problems related to Indonesian and Malaysians are interesting to study. The topic discussed in this study is the use of Indonesian and Malaysian personal pronouns. The main objective of this study is to compare the use of Indonesian and Malaysian personal pronouns from a semantic point of view. That is, the authors compare them in terms of lexical meaning. This is because the root of a vocabulary is the meaning of the dictionary. In this study, the type of qualitative method with a descriptive approach was chosen as the data analysis method.. The data collected is in the form of first, second, and third personal pronoun vocabulary. The data sources for this study are Kamus Besar Bahasa Indonesia and Kamus Dewan Bahasa Malaysia. Based on the results of the study, it was found that the use of Indonesian and Malaysian pronouns had differences and similarities. The difference can be seen from the number of meanings. In Indonesian, there are as many as 15 meanings, while in Malaysia there are as many as 20 meanings. The similarities can be seen in each personal pronoun.
\end{abstract}

Keywords: personal pronouns, Indonesian language, Malaysian language, semantics

\section{PENDAHULUAN}

Bahasa adalah sebuah alat yang digunakan manusia untuk berkomunikasi dalam memahami maksud lawan bertutur (Jauhari, 2017). Seiring berjalannya waktu, bahasa Indonesia berkembang dan bervariasi sehingga masyarakat umum sulit untuk memahami penggunaan bahasa tersebut (Nurfiana et al., 2019). Masalah variasi bahasa terutama pada bahasa Indonesia sering dikaitkan dengan bahasa Malaysia. Hal ini tentu menarik untuk dibahas karena berkaitan dengan identitas. Sarasati (2021) mengungkapkan bahwa identitas tidak dapat dilepaskan dari kehidupan manusia. Bahasa dan identitas bahasa Indonesia dan
Malaysia selalu diperdebatkan. Hal ini disebabkan adanya kemiripan dan kesamaan dalam penggunaannya sehingga sering dikaitkan dengan identitas.

Melihat permasalahan di atas, kajian ini bertujuan untuk mengungkapkan perbandingan pronomina pesona dalam bahasa Indonesia dan bahasa Malaysia. Penulis tertarik mengungkapkan perbandingan penggunaan pronomina pesona dalam tataran semantik. Artinya, penulis meninjau temuan ini berdasarkan kajian semantik leksikal. Perbandingan antara bahasa Indonesia dan Malaysia sangat unik untuk ketahui karena kedua bahasa ini memiliki kemiripan. Hal ini sejalan dengan pendapat dari Pro- 
madi (2012) bahasa terdapat perbedaan maupun persamaan pada bahasa Indonesia dan Malaysia. Hal tersebut disebabkan bahwa bahasa Indonesia dan bahasa Malaysia bersumber dari rumpun bahasa Malayu. Walaupun bahasa Indonesia dan bahasa Malaysia berakar dari bahasa Melayu, kosakata yang diserap masuk ke dalam kedua bahasa tersebut bersumber dari kosakata yang berbeda. Misal, bahasa Indonesia banyak menyerap kosakata dari daerah-daerah seperti Jawa, Sunda, dan sebagainya. Sumber rujukan pembentukan bahasa Indonesia dan bahasa Malaysia menimbulkan perbedaan dan persamaan (Ramza \& Abdullah, 2013).

Berdasarkan kacamata politik, bahasa Indonesia dan bahasa Malaysia tetap dianggap berbeda, tetapi dari unsur-unsur linguistik terdapat banyak persamaan (Phillips, 1973). Hal ini disebabkan rumpun Austronesia yang memiliki banyak kesamaan secara geografi yang berdekatan (Bellwood, 2000). Kondisi tersebutlah yang membuat penulis tertarik untuk mengetahui bagaimana penggunaan pronomina pesona dalam bahasa Indonesia dan bahasa Malaysia. Dalam kajian ini, penulis menggunakan istilah "bahasa Malaysia" bukan bahasa Malayu. Hal ini disebabkan penulis ini menonjolkan bahasa dari sebuah negara. Hal langkah yang telah mengingat bahasa Malayu menjadi bahasa kebangsaan dibeberapa negara seperti Singapura dan Brunei Darussalam.

Agar arah kajian ini semakin jelas, perlu kiranya penulis jelaskan sekilas, Apa itu pronomina persona? Umumnya, pronomina disebut juga sebagai kata ganti benda, orang, dan lainlain (Atmanegara, 2015). Secara spesifik, pronomina persona merupakan kata ganti yang mengacu pada orang yang dibicarakan, lawan bicara, dan diri sendiri. Contoh pronomina persona orang pertama adalah saya, aku, kami, dan kita. Pronomina persona untuk lawan bicara atau orang kedua adalah engkau, kamu, Anda, dan kalian. Adapun pronomina persona ketiga atau orang yang dibicarakan adalah mereka, dia, dan ia (Alwi et al., 2003). Dalam bahasa Malaysia, terdapat tiga bentuk pronomina personal yaitu pronomina persona pertama, pronomina persona kedua, dan pronomina persona ketiga (Harun, 2007). Jadi, dapat dikatakan bahwa kajian ini relevan dilakukan melihat jenis pronomina bahasa Indonesia dan bahasa Malaysia memiliki kesamaan.

Berdasarkan penelusuran penulis, kajiankajian perbandingan tentang pronomina bahasa Indonesia dengan bahasa lain seperti bahasa Indonesia dengan bahasa Prancis (Basuki, 1995; Henriette et al., 1989), bahasa Indonesia dengan bahasa Jepang (Gardika, 2012), bahasa Indonesia dengan bahasa Rusia (Danakusuma, 1995). Selain itu, Markhamah et al., (2017) dan Mulawarman (2018) mengkaji bahasa Indonesia dengan bahasa Arab serta Machu (2021) bahasa Indonesia dengan Bahasa Melayu Thailand. Adapun kajian perbandingan tentang pronomina bahasa Malaysia dengan bahasa lainnya pernah dilakukan oleh Sulaiman dan Yusoff (2020) bahasa Malaysia dan bahasa Inggris, Yazdi Amirkhiz, dkk. (2014) bahasa Malaysia dengan bahasa Iran, bahasa Malaysia dengan bahasa Cina (Lai \& Reduzan, 2013), bahasa Malaysia dan Perancis (Hassan, 1997). Hasil telaah pustaka tersebut, penulis menemukan bahwa masih sangat jarang kajian-kajian terkait bahasa Indonesia dan bahasa Malaysia terutama pada tataran kelas kata pronomina persona. Kajian-kajian terdahulu cenderung mengkaji perbedaan bahasa Indonesia maupun bahasa Malaysia dengan bahasa-bahasa diluar rumpun Malayu.

\section{METODE}

Metode kualitatif merupakan jenis metode yang digunakan dalam kajian ini. Jenis metode tersebut dirasa yang paling tepat digunakan dalam kajian ini. Hal ini merujuk pada pernyataan 
Sukmadinata (2017) bahwa metode kualitatif merupakan sebuah metode yang bertujuan untuk mendeskripsikan masalah atau variabel kajian. Selain itu, Sugiyono (2019) juga menyatakan bahwa hasil dari kajian kualitatif bersifat sementara dan dapat berubah di kemudian hari. Sejalan dengan dua pakar di atas, Mamik (2015) metode kualitatif tidak menggunakan model analisis statistik atau matematik. Dengan demikian, metode inilah yang paling sesuai digunakan untuk mengkaji perbandingan penggunaan pronomina persona bahasa Indonesia dengan bahasa Malaysia.

Data kajian ini adalah daftar kosakata pronomina persona dalam bahasa Indonesia dan bahasa Malaysia. Kosakata pronomina persona yang dijadikan rujukan dalam membandingkan bahasa Indonesia dan bahasa Malaysia ditampilkan sebagai berikut.

Tabel 1. Kosakata promomina persona

\begin{tabular}{|c|c|c|c|}
\hline $\begin{array}{l}\text { Bentuk } \\
\text { Pronomi } \\
\text { na Persona }\end{array}$ & $\begin{array}{l}\text { Pronomina } \\
\text { Persona } \\
\text { Pertama }\end{array}$ & $\begin{array}{l}\text { Pronomina } \\
\text { Persona } \\
\text { Kedua }\end{array}$ & $\begin{array}{l}\text { Pronomi- } \\
\text { na Perso- } \\
\text { na Ketiga }\end{array}$ \\
\hline Tunggal & saya, aku & $\begin{array}{l}\text { kamu, eng- } \\
\text { kau, anda }\end{array}$ & $\begin{array}{l}\text { dia, ia, } \\
\text { beliau }\end{array}$ \\
\hline Jamak & kita, kami & kalian & mereka \\
\hline
\end{tabular}

Pronomina persona pada tabel di atas merupakan kosakata pronomina persona yang sering ditemukan secara umum. Kosakata kata tersebut menjadi rujukan perbandingan makna secara leksikal (kamus) bahasa Indonesia dan bahasa Malaysia. Dengan demikian, sumber data makna leksikal kosakata pronomina pada tabel di atas bersumber dari Kamus Besar Bahasa Indonesi Edisi V dan Kamus Dewan Bahasa Edisi IV. Analisis data kajian ini menggunakan model analisis interaktif dari Miles and Huberman (dalam Sugiono, 2019, p. 322) Adapun tahapan dari tipe analisis interaktif tersebut dimulai dari menyajikan data, mereduksikan data, menyajikan data, dan menyimpulkan data.

\section{HASIL DAN PEMBAHASAN} Hasil

Bagian dalam pronomina persona bahasa Indonesia dan bahasa Malaysia secara umum dapat dikatakan sama. Masyarakat awam mengetahui penggunaan pronomina personal bahasa Indonesia dan bahasa Malaysia adalah sama. Namun, secara kamus menarik untuk diungkapkan secara jelas bagaimana pendefinisian kata pronomina persona bahasa Indonesia dan bahasa Malaysia sehingga dapat menambah pengetahuan penutur kedua bahasa tersebut. Berikut temuan, analisis data, dan pembahasan terkait perbandingan bahasa Indonesia dan bahasa Malaysia yang dilakukan.

Tabel 2. Pronomina Persona Pertama ( $A k u)$

\begin{tabular}{ll}
\hline Bahasa Indonesia & Bahasa Malaysia \\
\hline kata ganti orang perta- & kata ganti diri pertama \\
ma yang berbicara atau & (biasa dipakai sewaktu \\
yang menulis (dalam & berdoa kepada Tuhan \\
ragam akrab); diri & atau di antara orang \\
sendiri; saya & yang rapat perhubun- \\
& gan mereka, tetapi \\
& agak kasar terhadap \\
& orang yang perlu di- \\
& hormati)
\end{tabular}

Sumber: KBBI dan KDB

Dalam bahasa Indonesia, pronomina persona $a k u$ merupakan kata ganti diri bentuk tunggal. Kata ini digunakan untuk mengganti orang pertama yang berbicara. Kata ini digunakan dalam ragam akrab. Penggunaan pronomina persona $a k u$ dalam bahasa Malaysia juga sama digunakan untuk kata ganti diri pertama untuk konteks ragam formal. Namun, terdapat sedikit perbedaan yakni kata $a k u$ dalam bahasa Malaysia dapat digunakan untuk kata ganti diri ketika berdoa kepada Tuhan. Selanjutnya, kata aku tidak dapat digunakan untuk kata ganti orang yang lebih tua karena dianggap tidak sopan. 
Tabel 3. Pronomina Persona (saya)

\begin{tabular}{ll}
\hline Bahasa Indonesia & Bahasa Malaysia \\
\hline orang yang berbicara & ganti nama diri perta- \\
atau menulis (dalam ra- & ma (lebih halus daripa- \\
gam resmi atau biasa); & da aku), hamba: nama \\
aku & $\sim$ Ahmad \\
ya: --, Tuan! & ya, benar: $\sim$ encik; sa- \\
& haya. \\
\hline
\end{tabular}

Sumber: KBBI dan KDB

Terdapat dua makna pada kata saya dalam bahasa Indonesia dan Malaysia. Kata saya adalah pronomina persona tunggal. Berbeda dengan kata $a k u$, kata saya digunakan untuk konteks formal atau biasa. Begitupun dengan bahasa Malaysia, kata saya digunakan sebagai kata ganti diri pertama yang lebih halus dari kata $a k u$. Adapun makna kedua, kata saya dalam bahasa Indonesia bermakna ya. Contoh kalimatnya, saya, Tuan! Makna tersebut sama digunakan dalam bahasa Malaysia yang bermakna ya, benar. Contoh kalimatnya, saya Encik! Sederhananya, melalui pendefinisian dari kamus, tidak ditemukan perbedaan yang jelas dari pronomina personal saya dalam bahasa Indonesia dan bahasa Malaysia.

Tabel 4. Pronomina Persona Pertama (Kita)

\begin{tabular}{ll}
\hline Bahasa Indonesia & Bahasa Malaysia \\
\hline pronomina persona & kata ganti bagi diri \\
pertama jamak, yang & $\begin{array}{l}\text { orang yang bercakap ser- } \\
\text { berbicara bersama }\end{array}$ \\
dengan orang lain & (mendengarnya), saya \\
termasuk yang diajak & dan kamu semua: jan- \\
bicara & ganlah kerana dia pula, \\
& rumah tangga $\sim$ menjadi \\
& hancur \\
& orang bp saya serta sa- \\
cak saya & habat-sahabat saya dll \\
& (tidak termasuk orang \\
& yang dilawan bercakap), \\
& kami: boleh engkau men- \\
& ulis Quran nanti, $\sim$ orang \\
& beli \\
\hline
\end{tabular}

\begin{tabular}{cl}
\hline tidak ada & bp saya: awak yang men- \\
& gurus perkara itu, $\sim$ yang \\
& ditanyai \\
tidak ada & aku, saya (oleh raja, \\
& orang bangsawan atau \\
& orang besar-besar kepa- \\
& da orang kebanyakan \\
& atau orang bawahan- \\
& nya): tiada raja besar \\
& dalam dunia ini daripada \\
& $\sim$ dan tiada siapa pun \\
& yang tahu akan bilangan \\
& rakyat $\sim$ \\
& ark kata ganti bagi orang \\
& kedua, awak, kamu \\
& Br, bh awak (kata ganti \\
tidak ada & nama diri kedua dalam \\
tidak ada & bentuk tunggal); \\
\hline
\end{tabular}

Dalam bahasa Indonesia, kata kita memiliki dua makna. Pertama, digunakan untuk menyatakan kata ganti orang pertama berbentuk jamak. Kata ini digunakan untuk menyatakan penutur dengan lawan penutur. Adapun makna kedua digunakan untuk menyatakan pronomina personal tunggal tetapi dalam bentuk cakapan.

Dalam bahasa Malaysia, kata kita memiliki makna sebanyak enam makna. Kesatu, digunakan untuk menyatakan kata ganti diri orang pertama berbentuk jamak karena lawan bicara diikutsertakan. Kedua, digunakan sebagai kata ganti diri orang kedua berbentuk jamak dan lawan bicara tidak termasuk. Ketiga, kata ganti diri orang pertama tunggal bentuk cakapan. Keempat, kata ganti diri pertama tunggal dan hanya digunakan untuk raja dan bangsawan. Kelima, pronomina persona orang kedua yang berarti awak atau kamu. Keenam, untuk menyatakan pronomina persona tunggal. 
Tabel 5. Pronomina Persona Pertama (Kami)

\begin{tabular}{|c|c|}
\hline Bahasa Indonesia & Bahasa Malaysia \\
\hline $\begin{array}{l}\text { yang berbicara bersama } \\
\text { dengan orang lain (ti- } \\
\text { dak termasuk yang dia- } \\
\text { jak berbicara); yang } \\
\text { menulis atas nama ke- } \\
\text { lompok, tidak termasuk } \\
\text { pembaca }\end{array}$ & $\begin{array}{l}\text { saya sekalian (saya dan } \\
\text { rakan-rakan saya } \\
\text { semua): sudah lama } \sim \\
\text { menunggu awak di sini }\end{array}$ \\
\hline $\begin{array}{l}\text { yang berbicara (digu- } \\
\text { nakan oleh orang besar, } \\
\text { misalnya raja); yang } \\
\text { menulis (digunakan } \\
\text { oleh penulis) }\end{array}$ & $\begin{array}{l}\text { saya, aku: tidaklah } \\
\text { panjangkan cerita } \\
\text { tersebut. }\end{array}$ \\
\hline
\end{tabular}

Pronomina persona kami dalam bahasa Indonesia dan Malaysia terdapat dua makna. Makna pertama, kami digunakan untuk menyatakan kata ganti orang pertama berbentuk jamak tetapi tidak termasuk penutur yang diajak berbicara dalam bahasa Indonesia dan bahasa Malaysia. Kata ganti ini digunakan untuk mengatasnamakan kelompok, baik dalam tulisan ataupun lisan. Makna kedua, kami dalam bahasa Indonesia digunakan hanya orang besar seperti raja. Namun, bahasa Malaysia menggunakan kata kami dalam makna kedua untuk mengacu makna saya atau $a k u$. Artinya, kata kami pada makna kedua dalam berganti posisi menjadi pronomina tunggal karena setara dengan saya dan aku.

Tabel 6. Pronomina Persona Kedua (Anda)

\begin{tabular}{ll}
\hline Bahasa Indonesia & Bahasa Malaysia \\
\hline sapaan untuk orang & kata ganti diri kedua \\
yang diajak berbicara & (tidak membezakan \\
atau berkomunikasi (ti- & taraf, tingkat dan \\
dak membedakan & umur). \\
tingkat, kedudukan, & \\
dan umur) & \\
\hline Sumber: KBBI dan KDB
\end{tabular}

Dalam bahasa Indonesia dan Malaysia, kata Anda memiliki satu makna. Penggunaan kata Anda dalam bahasa Indonesia dan bahasa Malaysia adalah untuk menyapa orang yang diajak berbicara atau berkomunikasi. Penggunaan sapaan kata Anda ini tidak membedakan tingkat, kedudukan, ataupun umur. Jadi, kata Anda ini tidak terbatas penggunaannya.

Tabel 7. Pronomina Persona Kedua (Engkau)

\begin{tabular}{ll}
\hline Bahasa Indonesia & Bahasa Malaysia \\
\hline yang diajak bicara, & ganti nama diri kedua \\
yang disapa (dipakai & (untuk orang yang seta- \\
untuk orang yang sa- & raf atau yang lebih ren- \\
ma atau lebih rendah & dah, digunakan juga un- \\
kedudukannya), digu- & tuk Tuhan sewaktu ber- \\
nakan juga untuk ber- & doa), kamu, awak, la- \\
doa kepada Tuhan & wan aku; si engkau sl \\
(Engkau) & orang yg disebut eng- \\
& kau, orang rendahan: ji- \\
& kalau umpama $\sim$ si aku \\
& sekalipun, jika dengan \\
& titah tuanku patik seka- \\
& lian pertuanlah
\end{tabular}

Sumber: KBBI dan KDB

Dalam bahasa Indonesia dan Malaysia, kata engkau memiliki satu makna. Penggunaan kata engkau dalam bahasa Indonesia dan bahasa Malaysia adalah untuk menyatakan orang yang diajak bicara. Artinya, kata engkau digunakan sebagai kata ganti diri kedua berbentuk tunggal dalam bahasa Indonesia dan Malaysia. Kata engkau dapat digunakan dalam konteks lawan bicara yang sama atau lebih rendah. Selain itu, pronomina ini dapat digunakanv sebagai kata ganti Tuhan sewaktu berdoa (Engkau).

Tabel 8. Pronomina Persona Kedua (kamu)

\begin{tabular}{ll}
\hline Bahasa Indonesia & Bahasa Malaysia \\
\hline yang diajak bicara; & kata ganti diri kedua \\
yang disapa (dalam ra- & (orang yang menjadi \\
gam akrab atau kasar) & $\begin{array}{l}\text { lawan bercakap), awak, } \\
\text { engkau }\end{array}$ \\
\hline
\end{tabular}

Sumber: KBBI dan KDB 
Kata kamu dalam bahasa Indonesia dan Malaysia memiliki satu makna. Makna ini sama digunakan untuk kata ganti diri orang kedua berbentuk tunggal. Secara spesifik, kata kати dalam bahasa Indonesia digunakan dalam ragam akrab atau kasar. Namun, makna kata kamu dalam bahasa Malaysia tidak dijelaskan secara detail sehingga dapat dikatakan bahwa dapat digunakan secara umum.

Tabel 9. Pronomina Persona Kedua (kalian)

\begin{tabular}{ll}
\hline Bahasa Indonesia & Bahasa Malaysia \\
\hline $\begin{array}{l}\text { yang diajak bicara } \\
\text { yang jumlahnya lebih }\end{array}$ & sekalian \\
dari satu orang & \\
(dalam ragam akrab) & \\
\hline tidak ada & bp awak (kamu) semua: \\
& biarlah $\sim$ dulu, aku akan \\
& menyusul; $\sim$ memang be- \\
& gitu, suami isteri serupa \\
& saja; daftar $\sim$ kali-kali, \\
& sifir
\end{tabular}

Sumber: KBBI dan KDB

Dalam bahasa Indonesia, kata kalian merupakan pronomina persona orang kedua jamak. Umumnya, kata kalian digunakan untuk lawan pembicara dengan jumlah banyak, bisa dua orang, tiga orang, bahkan lebih. Penggunaan tersebut terbatas hanya digunakan untuk ragam akrab. Adapun dalam bahasa Malaysia, kata kalian bermakna sekalian yakni pronomina persona yang digunakan untuk menyatakan lawan bicara lebih dari satu orang. Selain itu, terdapat makna lain dalam bahasa Malaysia. Kata kalian dapat digunakan untuk kata ganti orang kedua jamak dengan tambah kata semua, tetapi makna ini terbatas hanya pada ragam cakapan. Misal, biarlah kalian dulu, aku akan menyusul.
Tabel 10. Pronomina Persona Ketiga (ia)

\begin{tabular}{ll}
\hline Bahasa Indonesia & Bahasa Malaysia \\
\hline orang yang dibicara- & kata ganti diri ketiga \\
kan, tidak termasuk & (bagi laki-laki atau \\
pembicara dan kawan & perempuan), dia: hari ni \\
bicara; dia & $\sim$ tidak datang ke peja- \\
& bat
\end{tabular}

Sumber: KBBI dan KDB

Dalam bahasa Indonesia dan bahasa Malaysia, kata ia merupakan pronomina persona bentuk ketiga tunggal. Kata tersebut dapat digunakan sebagai kata ganti diri ketiga, baik laki-laki atau perempuan. Sederhanannya, kata ini gunakan untuk menyatakan orang yang dibicarakan, tidak termasuk pembicara atau kawan pembicara.

Tabel 11. Pronomina Persona Ketiga (dia)

\begin{tabular}{ll}
\hline Bahasa Indonesia & Bahasa Malaysia \\
\hline $\mathrm{fcv}$ & $\begin{array}{l}\text { kata ganti diri ketiga (un- } \\
\text { tuk menegaskan atau mer- } \\
\text { endahkan); ia }\end{array}$ \\
\hline Sumber: KBBI dan KDB
\end{tabular}

Dalam bahasa Indonesia, pronomina persona dia adalah kata ganti diri ketiga berbentuk tunggal. Kata dia mirip penggunaannya dengan kata ganti ia. Adapun, kata dia digunakan sebagai kata ganti diri ketiga tetapi lebih spesifik dalam bahasa Malaysia. Hal ini disebabkan kata dia dalam bahasa Malaysia digunakan untuk menegaskan atau merendah yang dibicarakan. Hal ini menjadi pembeda antara definisi kata dia dalam bahasa Indonesia dan bahasa Malaysia.

Tabel 12. Pronomina Persona Ketiga (beliau)

\begin{tabular}{ll}
\hline Bahasa Indonesia & Bahasa Malaysia \\
\hline orang yang dibi- & kata ganti diri ketiga (un- \\
carakan (digunakan & tuk orang tua atau orang \\
untuk menghormat- & yang dihormati): mentuaku \\
inya) & seorang pendiam, tidak \\
& suka anak-anaknya terlam- \\
& pau banyak bercakap.
\end{tabular}

Sumber: KBBI dan KDB 
Dalam bahasa Indonesia dan bahasa Malaysia, kata beliau digunakan sebagai pronomina persona orang ketiga berbentuk tunggal. Kata beliau digunakan untuk kata ganti khusus orang tua atau yang lebih dihormati. Kata beliau ini dapat digunakan di kedua negara sebagai kata ganti diri yang lebih sopan untuk menyebut orang yang lebih tua.

Tabel 13. Pronomina Persona Ketiga (mereka)

\begin{tabular}{ll}
\hline Bahasa Indonesia & Bahasa Malaysia \\
\hline orang ketiga jamak (dia & mereka : (merka) $=\sim$ \\
dengan yang lain); & itu kata ganti diri keti- \\
orang-orang yang dibi- & ga (untuk bilangan \\
carakan: Toto bertemu & yang banyak), orang- \\
dengan Amir di jalan, & orang itu. \\
lalu -- pergi bersama-sa- & \\
ma ke sekolah & \\
\hline
\end{tabular}

Sumber: KBBI dan KDB

Dalam bahasa Indonesia dan bahasa Malaysia, pronomina persona mereka digunakan sebagai kata ganti diri ketiga untuk bilangan yang banyak. Artinya, kata ganti diri ini berbentuk jamak. Tidak ditemukan perbedaan dalam bahasa Indonesia dan bahasa Malaysia sehingga kata mereka dapat digunaka di kedua negara.

\section{Pembahasan}

Berdasarkan hasil analisis di atas, ditemukan bahwa jumlah makna secara keseluruhan bahasa Indonesia sebanyak 15 dan bahasa Malaysia sebanyak 20. Total makna ini dihitung dari 12 kosakata yang dianalisis. Dapat dikatakan bahwa bahasa Malaysia memiliki makna-makna penjelas lainnya dalam beberapa pronomina persona sehingga makna penggunaan pronomina bahasa Malaysia lebih banyak. Hal inilah yang membedakan penggunaan pronomina persona dalam bahasa Indonesia dan bahasa Malaysia. Namun, secara umum penggunaan 12 pronomina per- sona bahasa Indonesia dan bahasa Malaysia memiliki persamaan.

Sejalan dengan kajian (Aswan, 2021) yang telah dilakukan sebelumnya, ditemukan adanya perbedaan dan persamaan dalam bahasa Indonesia dan bahasa Malaysia. Meskipun demikian, temuan penulis dalam penelitian ini lebih spesifik dari kajian sebelumnya karena kajian ini hanya berfokus untuk membandingkan pronomina bahasa Indonesia dan bahasa Malaysia. Adapun kajian terdahulu bersifat terlalu umum dan mengkaji terlalu banyak jenis kosakata seperti verba, nomina, dan lain-lain. Selain itu, temuan ini dikuatkan dengan hasil kajian Zohri dan Ma'arof (2016); Purwaningsih dan Abdullah (2015); Parwinanto dan Abdullah (2014); Ramza dan Abdullah (2013) bahwa terdapat persamaan maupun perbedaan pada bahasa Indonesia dan bahasa Malaysia di berbagai jenis kosakata. Temuan penulis dalam kajian ini bersifat baru karena mengkaji pronomina persona bahasa Indonesia dan bahasa Malaysia dari tinjauan semantik leksikal. Namun, temuan ini dapat berimplikasi pada pengembangan bahan ajar yang kontekstual dan berbasis perbandingan kosakata untuk Sekolah Indonesia Luar Negeri yang ada di Malaysia. Misalnya, pemuatan hasil bandingan pronomina bahasa Indonesia dan bahasa Malaysia ke dalam bahan ajar. Hal ini merujuk pada temuan sebelumnya bahwa pembelajar khususnya anakanak Indonesia di Malaysia masih memiliki keterbatasan memahami kosakata (Aswan, 2020). Hal ini tentu sejalan dengan asumsi Suryaman (2006) bahwa bahan ajar yang digunakan di sekolah harus menarik bagi siswa. Salah satunya adalah dengan mamasukkan unsur-unsur yang dekat dengan siswa. Hal tersebut sejalan dengan upaya pemerintah dalam memajukan pendidikan Indonesia (Kurniasari \& Suhardi, 2019). 


\section{SIMPULAN}

Berdasarkan hasil pembahasan, penulis menyimpulkan bahwa dari 12 pronomina persona bahasa Indonesia dan bahasa Malaysia yang dibandingkan. Ditemukan perbedaan dan persamaan. Perbedaan dapat dilihat jumlah makna setiap kata pronomina personal. Dari 12 pronomina, bahasa Indonesia memiliki 15 makna sedangkan bahasa Malaysia memiliki 20 makna. Perbedaan ini disebabkan bahasa Malaysia lebih bervariasi penggunaan beberapa pronomina. Misal, pronomina persona kita yang dalam bahasa Indonesia digunakan hanya dua sedangkan bahasa Malaysia 6 makna penggunaannya. Adapun persamaan dapat dilihat pada setiap kata yang penggunaannya sama. Implikasi temuan ini dapat digunakan sebagai rujukan untuk pembuatan bahan ajar dan pengajaran bahasa Indonesia di Sekolah Indonesia Luar Negeri di Malaysia. Hal ini didasari pada karakteristik mayoritas pembelajar Sekolah Indonesia Luar Negeri yang lahir dan besar di Malaysia. Kajian ini masih dapat dikembangkan dengan mengkaji dari segi sosiolinguistik penggunaan pronomina persona bahasa Indonesia dan bahasa Malaysia. Hal ini disebabkan kajian ini masih terbatas pada makna leksikal belum pada tataran sosial.

\section{UCAPAN TERIMA KASIH}

Peneliti ingin mengucapkan terima kasih kepada Dosen Departemen Pendidikan Bahasa dan Sastra Indonesia yang telah memotivasi penulis hingga karya tulis ini selesai.

\section{DAFTAR PUSTAKA}

Alwi, H., Dardjowidjojo, S., Lapoliwa, H., \& Moeliono, A. M. (2003). Tata Bahasa Baku Bahasa Indonesia. Balai Pustaka.

Aswan, A. (2020). Implementasi Gerakan Literasi Sekolah di Community Learning
Center Sebagai Upaya Meningkatkan Kosakata Bahasa Indonesia Siswa. KLITIKA: Jurnal Pendidikan Bahasa Dan Sastra Indonesia, 2(1), 1-10. https://doi. org/https://doi.org/10.32585/klitika. v2i1.708

Aswan, A. (2021). Perbandingan Semantis Kosakata Bahasa Indonesia dan Bahasa Malaysia serta Pemanfaatannya sebagai Modul Membaca Sekolah Indonesia Luar Negeri di Malaysia [Universitas Pendidikan Indonesia]. http://repository.upi. edu/63129/

Atmanegara, S. W. (2015). Pedoman Umum Ejaan Bahasa Indonesia. Episentrum Books.

Basuki, T. (1995). Bentuk Persona Pertama dan Kedua Subjek dalam Bahasa Prancis dan Bahasa Indonesia. Humaniora, 1, 121-127. https://doi.org/https://doi. org/10.22146/jh.2005

Bellwood, P. (2000). Prasejarah Kepulauan Indo-Malaysia. Gramedia Pustaka Utama.

Danakusuma, I. N. (1995). Analisis Komparatif Pronomina Persona Bahasa Rusia dan Bahasa Indonesia Ditinjau Secara Morfosintaksis. Universitas Indonesia.

Gardika, M. M. (2012). Komparasi Ninshou Daimeishi Bahasa Jepang dengan Pronomina Persona Bahasa Indonesia [Universitas Padjajaran]. https://repository. unpad.ac.id/frontdoor/index/index/ year/2019/docId/123621

Harun, K. (2007). Pronomina Persona Bahasa Melayu Abad Ketujuh Belas. Linguistik Indonesia, 25(2), 11-19.

Hassan, R. (1997). Analisis Kontrastif Kata Ganti Nama Diri Bahasa Melayu dan Bahasa Perancis [Universiti Malaya]. http://studentsrepo.um.edu.my/1512/ 
Henriette, G., Martin, R., Tanamal, J., \& Sridwiani, T. (1989). Studi Kontrastif Pronomina Persona Bahasa Perancis dan Bahasa Indonesia. Universitas Indonesia.

Jauhari, A. (2017). Realisasi Kesantunan Berbahasa dalam Proses Belajar Mengajar Bahasa Indonesia Kelas XI Smkrealisasi Kesantunan Berbahasa dalam Proses Belajar Mengajar Bahasa Indonesia Kelas XI SMK. Diksi, 25(1), 46-56. https://doi. org/https://doi.org/10.21831/diksi. v25i1.18851

Kurniasari, F., \& Suhardi. (2019). Analisis Penerapan Pendekatan Saintifik pada Penugasan di Buku Teks Bahasa Indonesia Kelas VII SMP Berdasarkan Kurikulum 2013. Diksi, 26(1), 45-55. https:// doi.org/https://doi.org/10.21831/diksi. v26i1.16012

Lai, T., \& Reduzan, N. H. (2013). Kata Ganti Nama Diri Orang dalam Bahasa Cina dan Bahasa Melayu: Satu Analisis Kontrastif. PENDETA: Journal of Malay Language, Education and Literature, 4, 162-179.

Machu, M. (2021). Perbandingan Kelas Kata Bahasa Indonesia dengan Bahasa Melayu Thailand Selatan. Edu-Kata, 7(1), 3948. $\quad$ https://doi.org/https://doi. org/10.52166/kata.v6i1.1768

Mamik. (2015). Metodologi kualitatif. Zifatama.

Markhamah, Ngalim, A., Basri, M. M., \& Sabardila, A. (2017). Comparison of Personal Pronoun between Arabic and Its Indonesian Translation of Koran. International Journal of Applied Linguistics and English Literature, 6(5), 238-254. https://doi.org/http://dx.doi.org/10.7575/ aiac.ijalel.v.6n.5p.238

Mulawarman. (2018). Kata Ganti Orang (Pronomina Persona) dalam Bahasa Indonesia dan Bahasa Arab (Suatu Analisis
Kontrastif. BIDAR: Jurnal Ilmiah Kebahasaan Dan Kesastraan, 8(2), 35-55.

Nurfiana, N., Uswati, T. S., \& Nuryanto, T. (2019). Bentuk dan Makna Variasi Bahasa dalam Cerita Pendek Berbasis Kearifan Lokal. Diksi, 27(2), 110-121. https:// doi.org/https://doi.org/10.21831/diksi. v27i2.25014

Pawinanto, R. E., \& Abdullah, R. (2014). Perbezaan Makna Kata Belanja, Bilang dan Jimat pada Bahasa Melayu Malaysia dan Bahasa Melayu Indonesia. . . Fikiran Masyarakat, 2(2), 41- 45.

Phillips, N. (1973). Differences between Bahasa Indonesia and Bahasa Malaysia. Indonesia Circle. School of Oriental \& African Studies. Newsletter, 1(2), 7-9. https://doi.org/https://doi. org/10.1080/03062847308723526

Promadi, P. (2012). Perbedaan Semantik Antara Bahasa Indonesia dan Bahasa Malaysia: Satu Kajian Awal Upaya Mengelak Kesalahpahaman dan Perbedaan Budaya Antara Bangsa Serumpun di Asia Tenggara. Sosial Budaya, 9(2), 261-282. https://doi.org/http://dx.doi. org/10.24014/sb.v9i2.387.

Purwaningsih, N. M. S., \& Abdullah, R. (2015). Perbezaan Makna Kata Bingung, Ceroboh dan Pantas dalam Bahasa Melayu Malaysia dan Bahasa Indonesia. Fikiran Masyarakat, 3(1), 35-44.

Ramza, H., \& Abdullah, R. (2013). Penggunaan Kata Pelita, Tambang dan Tewas dalam Bahasa Melayu Malaysia dan Bahasa Melayu di Indonesia. Fikiran Masyarakat, 1(1), $1-8$.

Sarasati, R. (2021). Membangun Identitas Nasional Melalui Teks: Review Singkat terhadap Teks Sastra dalam Buku Teks Bahasa Indonesia. Diksi, 29(1), 69-76. 
Sugiono. (2019). Metode penelitian kuantitatif, kualitatif, dan R\&D. Alfabeta.

Sukmadinata, N. S. (2017). Metode penelitian pendidikan. PT Remaja Rosdakarya.

Sulaiman, M. Z., \& Yusoff, M. J. H. M. (2020). Bila dan Mengapa 'You'Menjadi 'Kita': Satu Analisis Perbandingan Inggeris-Melayu (When and Why 'You'Becomes 'Kita': A Contrastive English-Malay Analysis). GEMA Online ${ }^{\circledR}$ Journal of Language Studies, 20(4), 151-156. https://doi.org/http://doi.org/10.17576/ gema-2020-2004-09

Suryaman, M. (2006). Dimensi-Dimensi Kontekstual Di Dalam Penulisan Buku Teks Pelajaran Bahasa Indonesia. Diksi, 13(2), 165-178. https://doi.org/10.21831/diksi. v13i2.6456
Yazdi Amirkhiz, S. Y., Bakar, K., \& Hajhashemi, K. (2014). The Use Of Personal Pronouns: A Comparison between Iranian and Malaysian Dyads. International Journal of Applied Linguistics \& English Literature, 3(1), 245-248. https://doi. org/http://dx.doi.org/10.7575/aiac. ijalel.v.3n.1p.245

Zohri, M., \& Ma'arof, D. Z. B. (2016). Perbezaan Makna Kata Penyelidikan, Solar dan Markah pada Bahasa Melayu Malaysia dan Melayu Indonesia. . . Fikiran Masyarakat, 4(2), 80-83. 